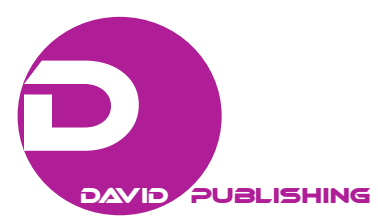

\title{
Competition Law in the GCC Countries: The Tale of a Blurry Enforcement
}

\author{
Maria Casoria \\ Royal University for Women, Riffa, Kingdom of Bahrain
}

\begin{abstract}
The study aims at making additions to the literature on the competition laws in the Gulf Cooperation Council (GCC) countries, and emphasizes that the application of the rules in force represents the weak point of systems in which the competition policy awareness is much needed but still anchored at a rudimentary stage. This is especially evident when considering that, although such laws have been built up following the European Union model as regards to the forbidden practices, and the US system-with its combination of monetary fines and criminal approach—for the sanctions, the establishment of a legal environment "friendly competition" is far from effective enforcement. After providing an overview of the competition laws passed by the six GCC members, the paper highlights that, notwithstanding the wide arsenal of legal tools to curb possible anticompetitive practices made available under the national regimes, in all countries role and powers of the competition authorities are somewhat underrated. Due to such generalized lack of implementation, the article underlines the need for effective enforcement standards accompanied by a joint harmonized action against illegal competition to be undertaken at regional level in order to facilitate the flow of commerce, and strengthen the economy in the GCC marketplace.
\end{abstract}

Keywords: Arab Gulf States, competition authorities, competition law, economic integration, enforcement, Gulf Cooperation Council

\section{Introduction}

In today's economy understanding the rationale of both national and international competition regimes is a necessary and prudent part of any successful commercial strategy. Competition rules may indeed produce a potential impact on every aspect companies' business plan and activities, since they govern a broad range of conducts such as interaction with competitors, obtaining and maintaining a dominant market position, forming supplier and customer arrangements, participation in trade associations, and conduct in joint ventures and corporate mergers and acquisitions. Therefore, whether a company is large or small, placed in a developed or developing country, if it is considering to create a business alliance, to move into a new market, to take a new tack with its competitors, to implement an innovative production, marketing, or distribution strategy, or to grow through corporate development, the requirements laid down by the competition laws shall be taken into account; in fact, the consequences for non-compliance can be severe.

Maria Casoria, Ph.D., Dr., assistant professor, College of Law, Royal University for Women, Riffa, Kingdom of Bahrain.

Correspondence concerning this article should be addressed to Maria Casoria, Al Muaskar Highway, P.O. BOX 37400, West Riffa, Kingdom of Bahrain. 
Over the last decades some developing countries have been undergoing substantial reforms to promote trade liberalization and protect market operators outside the national boundaries (Fox \& Gal, 2014). The legislative trend has affected especially the Middle Eastern countries, which are trying to hinder the high concentration of wealth in the hands of few local families (Dabbah, 2012; Lahouel, 2011). In this geographical area a main role is played by the six Arabian Gulf States (Bahrain, Kuwait, Oman, Qatar, Saudi Arabia, and United Arab Emirates) due to the huge incomes originated by oil-refining and gas extraction and the high degree of homogeneity in all respects such as the religious, cultural, and linguistic linkages, the similarity of social conditions, and the nature of the contemporary economic challenges. Most importantly, the fact that such States are part of a political, economic, and social alliance founded in Riyadh on 25th May 1981 and known as Cooperation Council for the Arab States of the Gulf or simply Gulf Cooperation Council (hereinafter GCC) represents the added value towards the enforcement of specific pro-competitive rules in the common regional market (Colombo, 2014; Borea, 2014; Youngs, 2011; Alasfoor, 2007).

Indeed, as consequence of the gradual shift in the control of the production from the public sector to the private entrepreneurs who are affecting the worldwide economy, each GCC country has enforced competition rules serving the objectives of efficiency and fairness in performing commercial activities, and with the aim to minimize the high market concentration dominating the Gulf systems. Furthermore, since few years the GCC members have been debating the feasibility of a harmonized regime to be enacted at regional level, but the landmark project has not been completed yet, with a draft of the joint competition law discussed in several official meetings without the consequential imprimatur from the representatives of the local governments.

In the light of the above considerations, the paper will examine the legislation passed in all GCC countries, analyze the legal assessment for the different types of anti-competitive conducts, and highlight the aspects which require further implementation for an effective enforcement of the rule of law.

\section{Literature Review}

The interpretation of the competition laws enforced in the GCC countries is the topic disregarded by the majority of scholars, whose interest is mostly directed towards the antitrust regimes operational in other areas of the Middle East. Moreover, the scholarly debate often undermines the vital role played by the competitive dynamics for entrenching the market mechanisms and consolidating the process of trade liberalization in developing countries. Consequently, the literature utilized for conducting the study is somewhat generalist, and ranges from papers on the GCC politics to sources that provide a very broad overview on the growing importance of the economic integration in the Gulf region.

\section{Research Methodology}

The paper focuses on the analysis of the existent legislation and compares the different legal rules in force in the six States concerned, in the attempt to underline similarities and differences among them. It also tackles the very few decisions adopted by the competent competition authorities, as published in the annual reports of these public bodies.

The study tries to draw attention over a topic that might make the difference for boosting the wealth of countries which are dependent on the exploitation of natural sources but are trying to stabilize their economy under the banner of the "diversification", as recently stated by the local decision makers in development plans and national strategies known as "visions". 


\section{Research Results}

Saudi Arabia, Qatar, and Kuwait have been the first three GCC countries to pass a specific competition law between 2004 and 2007, following on the heels of this group, by United Arab Emirates and Oman, respectively in 2012 and 2014. In a hybrid position Bahrain, a legislation combines together consumer protection and competition rule.

Overall the laws ban a range of anti-competitive practices that are also prohibited by equivalent regulations in Western systems. The main points of divergence can be identified in the limited scope of application, since the pro-competitive rules do not apply to governmental acts or acts of entities supervises or are controlled by the State, and in the weak enforcement, which seems to exist only on paper but lacks of effective deterrent effects.

\section{Saudi Arabia}

The Saudi regulation comprises of the Royal Decree No. M/25 of the 4th Jumada Awal 1425 Hejra, corresponding to the 22nd June 2004 Gregorian, and the amending based on the Royal Decree No. 24/M dated 11/4/1435 H corresponding to the 11th February 2014 Gregorian, plus the Implementing Regulations promulgated under the resolution of the Competition Council No. 126 dated 4/9/1435 AH corresponding to the 1st July 2014 Gregorian. As a whole, these laws set forth the basic principles regarding dominant position, anticompetitive restraints, exceptions to state-owned enterprises and block exemptions, economic concentration, pleading procedures, and investigation conducted by the Competition Protection Council (Daudpota, 2015).

The basic rule of law establishes that its provisions apply to all firms working in the Saudi markets except for public corporations and wholly-owned state companies, and then provides a definition of anticompetitive agreements, dominant position, and merger operations (art. 4-7). Furthermore, it regulates composition, powers, and prerogatives of the Competition Council established, with the Royal Order No. A/92 of the 6th Ramadan 1425 Hejra corresponding to 20th October 2005 Gregorian, as an independent authority but operating under the umbrella of the Ministry of Commerce and Industry (art. 8-11), and determines the fines to be issued for the hypothesis of violations decided by a Committee appointed within the Council. Peculiarly, in this regard, the possibility of imprisonment for those who have realized a direct or indirect benefit from the disclosure of a "secret related to the job" made by any person involved in the performance of business activities. The decisions issued by the Council may be appealed before the Board of Grievances in accordance with its law and regulations, and the competition law recognizes to natural or corporate persons the right to claim compensation for damages.

On the other side the Implementing Regulations, after a list of the general aims pursued by the competition rules, extend their scope of application beyond the limits set up in the competition law, by establishing that the provisions shall also apply to any activity taking place abroad, which leads to consequences contrary to fair competition within the Kingdom (art. 3). The same article broadens the exception to the application of the competition laws - previously granted only to wholly-owned state companies - to any commercial operator that deals with state-owned establishments.

The legislation fixes parameters to assess the impact on the relevant market of agreements and practices between competing or potentially competing entities, and contains a list of conducts that can be qualified as abuse of dominant position by the Council (art. 4-10). Moreover, the Regulations provide for a system of exemptions applicable to any agreement or practice that will lead to the improvement in the performance of entities and 
realize benefits to the consumer exceeding the impacts of restriction of free competition (art. 11), and describe the proceedings thereof (art. 12-18). It follows a specific section on the procedures for the notification of economic concentration applications to the Council which, after reviewing the effects of the operation, decides on its refusal and approval—simple or conditional, and can take all the necessary precautionary measures to safeguard free competition (art. 19-33). The last two parts cover the enforcement procedures of the competitive tenets by the Council (art. 34-56) and its internal Committee for the settlement of violations (art. 57-75).

\section{Qatar}

When compared with the Saudi legislation, at first glance the Qatari law seems straightforward; nonetheless it prohibits a wide range of anti-competitive practices, and prescribes some fundamental rules aiming to protect the competition apparatus. The Competition Act No. 19 of 2006 on the Protection of Competition and Prevention of Monopolistic Practices defines its scope of application declaring that international treaties and agreements shall prevail upon national provisions for the protection of competition and the prevention of monopolistic conducts. Then, it regulates anticompetitive agreements and practices, and the misuse through unlawful practices undertaken by any person who exercises control or domination over commercial activities; however, for both violations the legislator stipulates the possibility to be exempted if doing so may be beneficial for the consumer. Another general exemption is granted to sovereign ventures of the State and to all entities subject to State direction and supervision. With regard to operations of concentration and merger, the law establishes a system of prior notification to the "Committee for the Protection of Competition and Prevention of Monopolistic Practices” created within the Ministry of Economy and Commerce, which has 90 days for issuing a decision; the sole exception is represented by mergers, which, in the Committee's view, assist economic development in a manner that compensates for any detriment to competition (art. 10).

The enforcement is entrusted to the aforementioned Committee, which exercises its duties ex officio or upon request of any person aware of anticompetitive conducts in collaboration with the Ministry of Commerce (art. 7-9). The penalty can be either the payment of a fine, identified between the minimum and maximum amount set by the law, or a criminal punishment save, in the latter hypothesis, the written permission from the Minister following the proposal of the Committee. In all cases, the Court shall order the seizure of any profit resulting from the contravention of competition rules.

The closing provision lays down two main principles of liability: the first, is the personal responsibility for the manager of the legal entities involved in a violation if he was aware of the violating acts and the failure to carry out his duties contributed to the offence; the second, is the joint liability of the legal entity for anticompetitive conducts undertaken by the employees in its name or in its interest.

\section{Kuwait}

The Kuwaiti system protects the competitive dynamics through the Law No. 10 of 2007, as amended by the Law No. 2 of 2012, which came into effect on August 2009 and repealed the previous regulations on illegal competition contained in the Commercial Code. Beside the general definitions, the law expands its applicability to the violations committed in Kuwait, as well as to those taking place abroad but with harmful effect in the internal market. The exceptions to the scope of the law are not only limited to state-owned entities, as stipulated in the Saudi and Qatari regulations, but cover all the activities required by a particular law, the cooperation between companies that aim to facilitate market activity, and the commercial entities that operate in research and development. 
The law establishes the Authority for the Protection of Competition with the duty to evaluate any agreement and practice alleged to be anticompetitive with the only exception for the agreements or practices able to achieve a clear benefit to consumers that may outweigh the limitation of the free competition, and to assess the cases of abuse of dominant position. Like the legislation previously examined, a prior notification of acquisitions and mergers to the Authority is required if a natural or legal person, after such operations, will acquire the direct or indirect control over a specific market and this control will represent more than the $35 \%$ of the relevant market. However it has to be noted that despite the fact that the members of the Board of Directors and the Executive Director of Board have been appointed by the Government with Decree No. 137 of 2015, currently the Authority is only a formal body without effective powers.

When it comes to the penalties, the violator can be fined KD 100.00 or an amount equal to the gain illegally acquired, whichever is higher, and the sum can be doubled in case the infringement is repeated. Furthermore, the Authority has the discretion to order the confiscation of the commercial activity or its restriction for a maximum of three years.

\section{United Arab Emirates}

Moving on to the countries that enacted an ad hoc regulation on anticompetitive behaviors and monopolistic practices at a later date, the first legislation to scrutinize is the Emirati one-Federal Law No. 4 of 2012, implemented on 27th October 2014 by adopting, with resolution of the Council of Ministers No. 37 of 2014, the executive regulations to the law, which resembles in the general structure to the regional counterparts but nonetheless reveals few elements of differentiation.

If the objectives of the legislation and the types of practices are similar to those regulated in the other States, the legislation governs even the establishments which simply hold intellectual property rights inside or outside the national boundaries (art. 3). Additionally, the subjects of the law are partially different, since the exception granted to the Government and its related entities by the other regional legislators are here extended to the enterprises operating in some business sectors, that are telecommunications, financial services, cultural activities, oil and gas, pharmaceutical products, postal services, electricity and water, and transportation. Moreover, entities with a small and medium market share or whose agreements might have a negligible effect on the relevant market fall into the de minimis category.

The Ministry of Economy is the regulatory authority responsible for the enforcement along with a special Committee of competition regulation to be established as advisor to the Minister with the duty of studying issues relating to the implementation of the Competition law and making proposals on further protection procedures (chap. 6, 7, and 9). Interestingly, the Competition lawsuits are considered as urgent cases and, therefore, the competent court shall issue a decision on ceasing or preventing any act before the final judgment.

As far as the sanctions are concerned, the law enumerates a number of penalties which range from the payment of a fine between a minimum and maximum amount to the suspension or closure of the business. In general terms, the penalty system is almost immune from the criminal halo which affects the neighborhood regulations.

\section{Oman}

The law for the protection of competition and prevention of monopoly, Royal Decree Bearing No. 67 of 2014, came into effect in Oman on 8 December 2014, the day immediately after its publication. The legislation has a broad scope of application; it regulates all the activities related to production, trade, services, and any 
other economic or commercial activity practiced in the country or even outside but with consequences prevailing in the Sultanate. It extends its applicability to violations related to intellectual property rights in as much as their use has a negative or adverse impact on competition. On the other side it introduces a new kind of exception to the applicability of the competition rules, since it does not cover the conducts connected to research and development carried out by any public or private body. Indeed, a block exemption is granted to agreements, procedures, or business activities that entail consumer protection and benefit in the cases specified by the law.

With regard to the anticompetitive practices, the prohibited arrangements are divided into two categories: "monopolistic agreements", whose aim is to create or maintain a monopoly over import, production, distribution, sale, purchase, or trade of goods or to undertake any monopolistic practice that may negatively affect the market; "anticompetitive or restrictive agreements", which are those concluded for the purpose to prevent, eliminate, or undermine competition by performing several activities listed in art. 9 of the law itself, following provisions on the abuse of dominant position and creation of economic concentrations, with the threshold for clearance fixed in the $50 \%$ of the relevant market (art. 10-11).

The supervision over the competition rules is bestowed to an Authority named Public Authority for the Customer Protection, although the law does address only the hypothesis of anticompetitive violations, which, unlike the other regional systems, exercises its powers independently from any other governmental body ex officio or upon request (art. 12-17). The penalty structure appears as a combination of criminal sanctions and fines. Its peculiarity is that the amount to be paid is tied to the benefit gained out of the practice, calculated as a percentage of the annual sales and not in a fixed amount. Consequently, since the penalties are proportionate to the size of the violating body, the system seems to be fairer.

Finally, what makes the Omani rule of law more close to the western model is the so called "leniency provision”, which empowers the competent court to mitigate or discharge the penalty of the violator that timely reports the infringement to the Authority, and contributes to uncovering the anticompetitive conduct by submitting all the evidences in its possession at any stage of the administrative or judicial proceedings.

\section{Bahrain}

In the GCC area Bahrain is the only country with no separate competition legislation in force. However, some rules against unfair competition and monopolistic practices are laid by the Commercial Code No. 7 of 1987, and by the Law No. 35 of 2012 on the consumer protection, which contains a specific chapter named "Rules of Competition and Monopoly and Manifestations of Breach of their Rules". In more details, the Commercial Code banishes all the activities that may affect negatively the functioning of the free market and punishes the entities that undertake behaviors harmful to the competitors, especially by attracting their customers; the Consumer Protection Law, following the path of the Qatari regulation, starts the section concerned with a declaration of supremacy of the international conventions and agreements operating in the Kingdom.

The sectorial law proceeds with a provision on the anticompetitive restraints, which are all prohibited except for those agreements that, despite the anticompetitive limitations, may result in reductions of costs or improvement of production or distribution conditions with a benefit to the consumers (art. 13). Another provision prohibits harmful commercial or monopolistic practices but refers to the implementing regulations - to be subsequently enforced-for the identification of rules and procedures related to such practices. Unlike the other laws, the regulation of the economic concentration between commercial entities is completely missing. 
The Bahraini legislation entrusts the enforcement to the Minister of Commerce, depositary of special powers for curtailing the prices of necessary goods in the event of crises or exceptional circumstances which lead to unusual increases; furthermore, the Minister has the faculty to suspend the import, export, and display of certain products, and to order the withdrawal or destruction of them in case of immediate or imminent threat in the market.

The penalty system does not substantially deviate from the one adopted in nearby countries. The only difference is represented by the power of the Ministry of Industry and Commerce to conduct, upon recommendation of the Consumer Protection Directorate, an administrative proceedings which begins with a warning letter to the violators and proceeds, in case of non-compliance, with the adoption of a resolution to close the commercial establishment for a period not exceeding three months or to strike off the entity from the specific ministerial registry.

\section{Discussion}

Despite the variety of powers conferred by the domestic laws to the Competition Authorities, tasked—at least on paper-with engaging in the control over competitive activities to safeguard free commerce, bar monopolies and other harmful practices, investigate complaints, supervise mergers and acquisitions, the review of the competition regimes in the GCC displays a general lack in the enforcement of the legal instruments.

Leaving aside the Saudi Competition Protection Council, which is the most advanced in terms of monitoring the conducts that can damage the relevant market, the status quo in the other States seems underdeveloped when considering the number of investigations and cases already decided. In the recent past the Saudi Authority has undertaken several procedures for/to the authorization of economic concentrations, as documented in its Annual Reports; the body also received a good number of complaints and since its establishment it has been deciding almost 60 cases in different economic sectors, mainly food and beverages, constructions, medical products, and telecommunications (Alotaibi, 2016).

It follows closely behind the Omani Public Authority for the Customer Protection, similar to the Saudi one for the organizational structure, but different as per competencies, given that it deploys its forces in fighting anticompetitive behaviors as well as in defense of consumers; and indeed the case law on this second aspect is far larger. In any event some laws in force in related business fields grant other Authorities the power to supervise the respect of fair competition in various areas of activity, namely, telecommunication, information technology, and capital markets.

A mixed system has been adopted in Qatar and United Arab Emirates, where the power to oversee the cornerstones of competition is divided between the Ministry of Economy and a specialized Committee, which in the first case is the principal addressee of the claims, whereas in the second hypothesis will be in charge, once established, of secondary duties connected with study and research activities. As it is evident, in both cases the Competition Authority is meant to be dependent from the governmental power.

In a different Bahrain and Kuwait, with the former that confers the power to act as watchdog of the market mechanisms to a Directorate part of the Ministry of Industry and Commerce, in charge of both consumer protection and anticompetitive infringements. And the latter that has already established a Competition Protection Bureau which, however, is not yet in operation despite that the Kuwaiti legislation has been one of the first to be enacted in the regional block. 


\section{Conclusion}

The analysis of the competition regimes enacted in the Arab Gulf States underlines that such systems are not particularly advanced in terms of competition law culture and awareness. This is especially evident when considering that, although the laws have been built up following the European Union model as regard to the forbidden practices, and the US system, with its combination of monetary fines and criminal approach, for the sanctions, the establishment of a legal environment "friendly competition" is still far from an effective implementation.

A driving force behind the introduction of competition legislation in the area comprising the GCC has been the attempt to comply with the legal and economic requirements set by the World Trade Organization, in order to gain the benefits offered by the access to such an institutional body. However, the fact that key sectors of the local economy, namely, oil-refining and gas extraction, are excluded from this sectorial regulation inasmuch they are under the control of governmental establishments, along with the prevalence of family businesses in the region, makes it essential to rethink at the proper strategy for a more effective protection of fair competition, transparency, and openness in the market.

At national level, among the potential advantages of the concrete enforcement of the domestic competition laws already effective, it is worthy to enumerate economic growth, poverty alleviation, wealth redistribution, development in research and technology, economic diversification. In any case, for the regulation to succeed, it might be desirable for the extension of the scope of the law to public and wholly state-owned corporations due to the significant role of the state ownership, along with the reinforcement of role and powers of the Competition Authorities.

On the other hand, the approval of a unified rule of law might boost the business activities between the Member States, especially with regard to the cross-border mergers, and promote intra-regional trade in line with the economic cooperation project in place in the region. Moreover, since the Arabian Gulf countries aim at becoming a major hub for international commerce and a strategic gateway to the Asian and Middle Eastern countries, the adoption of a joint action plan to overwhelm illegal competition seems to be the fundamental step to transform the local market in a more attractive place for foreign investments.

Undoubtedly the development of an efficient and dynamic competition system is a long process, which starts but is not limited to the enactment of a legal text. The future of the competition policy in the GCC much relies on the will and determination of relevant ministries and protective authorities in enforcing rules capable to ban all the conducts which can lead to breach, limitation, or prevention of free competition in the domestic or in the common market, with the final purpose to strengthen economic relationships with international partners and promote commercial activities across boundaries.

\section{References}

Alasfoor, R. (2007). The Gulf Cooperation Council: Its nature and achievements. A political analysis of regional integration of the GCC states 1974-2004. Lund, SE: Lund University Press.

Alotaibi, M. (2016). Saudi Arabia: Council of competition. The African and Middle Eastern Antitrust Review. Retrieved from http:/globalcompetitionreview.com/reviews/77/sections/290/chapters/3137/saudi-arabia-council-competition/

Borea, P. (2014). Studies on Arab regionalism: The Gulf Cooperation Council. Rome, IT: Aracne.

Colombo, S. (2014). Bringing the gulf: EU-GCC relations at a crossroads. Rome, IT: Nuova Cultura.

Dabbah, M. M. (2012). Competition law and policy in the Middle East. Cambridge, UK: Cambridge University Press.

Daudpota, F. (2015). Competition law in the Kingdom of Saudi Arabia, Riyadh, KSA. 
Daudpota, F. (2015). Competition law in the Kingdom of Saudi Arabia. Riyadh, KSA: Kindle Edition.

Fox, E. M., \& Gal, M. S. (2014). Drafting competition law for developing jurisdictions: Learning from experience. New York University Law \& Economics Working Papers, 374.

Lahouel, M. E. H. (2011). Competition laws in MENA: An assessment of the status quo and the relevance of a WTO agreement.

Economic

Research

Forum.

Retrieved

from

http://siteresources.worldbank.org/INTCOMPLEGALDB/Resources/Hedi.pdf

Youngs, R. (2011). The gulf region in the global economic context. Cambridge, UK: Gulf Research Centre. 